\title{
Does prolonged $\beta$-lactam infusions improve clinical outcomes compared to intermittent infusions? A meta-analysis and systematic review of randomized, controlled trials
}

\author{
Pranita D Tamma ${ }^{1 *}$, Nirupama Putcha ${ }^{2}$, Yong D Suh ${ }^{3}$, Kyle J Van Arendonk ${ }^{4}$ and Michael L Rinke ${ }^{5}$
}

\begin{abstract}
Background: The emergence of multi-drug resistant Gram-negatives (MDRGNs) coupled with an alarming scarcity of new antibiotics has forced the optimization of the therapeutic potential of available antibiotics. To exploit the time above the minimum inhibitory concentration mechanism of $\beta$-lactams, prolonging their infusion may improve outcomes. The primary objective of this meta-analysis was to determine if prolonged $\beta$-lactam infusion resulted in decreased mortality and improved clinical cure compared to intermittent $\beta$-lactam infusion.

Methods: Relevant studies were identified from searches of MEDLINE, EMBASE, and CENTRAL. Heterogeneity was assessed qualitatively, in addition to $\mathrm{I}^{2}$ and Chi-square statistics. Pooled relative risks (RR) and 95\% confidence intervals $(\mathrm{Cl})$ were calculated using Mantel-Haenszel random-effects models.

Results: Fourteen randomized controlled trials (RCTs) were included. Prolonged infusion $\beta$-lactams were not associated with decreased mortality ( $n=982 ;$ RR 0.92; 95\% Cl:0.61-1.37) or clinical cure ( $n=1380 ;$ RR $1.0095 \%$ Cl:0.94-1.06) compared to intermittent infusions. Subgroup analysis for $\beta$-lactam subclasses and equivalent total daily $\beta$-lactam doses yielded similar results. Most studies had notable methodological flaws.

Conclusions: No clinical advantage was observed for prolonged infusion $\beta$-lactams. The limited number of studies with MDRGNs precluded evaluation of prolonged infusion of $\beta$-lactams for this subgroup. A large, multicenter RCT with critically ill patients infected with MDRGNs is needed.
\end{abstract}

Keywords: $\beta$-lactams, infusion, multi-drug resistant Gram-negatives, antibiotics

\section{Background}

In the last several years, a progressive increase in resistance among Gram-negative pathogens has continued unabated. The emergence of multi-drug resistant Gramnegative organisms (MDRGNs) coupled with an alarming scarcity of new antibiotic classes in the pipelines of the pharmaceutical industry has forced the healthcare community to optimize the therapeutic potential of currently available antibiotics [1].

The primary determinant of $\beta$-lactam efficacy is the duration of time in which the non-protein bound

\footnotetext{
* Correspondence: ptamma1@jhmi.edu

'Department of Pediatric Infectious Diseases, Johns Hopkins Medical Institutions, Baltimore, MD, USA

Full list of author information is available at the end of the article
}

drugconcentration (fT) exceeds the minimum inhibitory concentration (MIC) of the organism $(\mathrm{fT}>\mathrm{MIC})$ [2]. $\beta$ lactam antibiotics have traditionally been administered by intermittent infusion. With intermittent dosing, $\beta$ lactams attain a high peak concentration, but short halflives can lead to precipitous drops in serum drug levels. Optimizing fT $>$ MIC is particularly difficult for organisms with elevated MICs. Pharmacokinetic studies have shown that prolonging the infusion time provides more consistent serum levels and maximizes $\mathrm{fT}>\mathrm{MIC}$ [3-7]. It is unclear, however, if this translates to improved patient outcomes.

Several trials comparing clinical outcomes of prolonged infusion $\beta$-lactams with standard dosing have been completed, with conflicting results [7]. Moreover, 
the interpretation of these studies remains controversial as most trials were conducted with small numbers of patients. We performed a systematic review and metaanalysis of randomized controlled trials (RCTs) investigating the efficacy of prolonged infusion $\beta$-lactam therapy compared with intermittent infusion $\beta$-lactam therapy with regards to mortality, clinical cure, and adverse effects. The primary objective was to determine if prolonged infusion of $\beta$-lactam antibiotics resulted in improved patient survival and clinical cure compared to intermittent dosing of $\beta$-lactam antibiotics. The secondary objective was to determine if prolonged infusion of $\beta$-lactam antibiotics resulted in increased adverse effects compared to standard, bolus dosing of $\beta$-lactam antibiotics.

\section{Methods \\ Definitions}

Prolonged infusion of $\beta$-lactam antibiotics consisted of either extended infusion or continuous infusion of the antibiotic. Extended infusions were defined as intermittent infusions lasting $\geq 3$ hours, whereas continuous infusion involved administration over a 24-hour period at a fixed rate [8]. Intermittent infusion of $\beta$-lactam antibiotics served as the control group and was defined as standard infusions of antibiotics based on package inserts. Identical $\beta$-lactams did not need to be administered for both study arms in a particular trial, so long as both drugs were $\beta$-lactam antibiotics with similar spectrums of activity.

\section{Outcomes}

The primary outcomes of the analysis were mortality and clinical cure. Mortality was assumed to be in-hospital mortality, a biologically relevant period in which death can be considered a consequence of treatment failure. Clinical cure was defined by the discretion of the authors because of the heterogeneous nature of the study population, pathogens involved, and the sites of infections. The secondary outcome of the analysis was adverse effects during $\beta$-lactam treatment.

\section{Data sources}

Relevant studies were identified from searches of MEDLINE, EMBASE, and Cochrane Central Register of Controlled Trials (CENTRAL) without imposing language or study period restrictions. Databases were searched on February 11, 2011 utilizing the final search strategy. Appendix A contains the complete electronic search strategy. Search terms for MEDLINE included descriptors of population, drug, and administration schedule. A similar method was employed to search EMBASE, with different limits to capture clinical trials of humans and to exclude review articles and case reports. Highly sensitive RCT filters were incorporated for MEDLINE and EMBASE searches. For CENTRAL a strategy similar to that used for MEDLINE was utilized, without the highly sensitive term for clinical trials. In addition, due to the smaller size of the CENTRAL database, some terms in the search strategy were altered to increase the sensitivity of the search. Two translators with a medical background were used for any non-English articles encountered. After a final list of included articles was compiled, Web of Science (accessed March $2^{\text {nd }}, 2011$ ) and a review of the citations for each article were conducted to search for further potentially relevant articles to include. First authors of studies needing further clarification were contacted [5,9-12].

\section{Study Selection}

Two independent reviewers examined studies for inclusion at both title/abstract and full-text review stages. Any discrepancies between reviewers were resolved by consensus of all study members. During initial title and abstract selection, a broad criterion for inclusion was encouraged and consisted of any study comparing prolonged infusion $\beta$-lactams to intermittent $\beta$-lactam infusion in humans. Full text review was then conducted with more conservative inclusion requirements. A study was considered eligible if (1) it was an RCT, (2) it compared prolonged infusion $\beta$-lactam antibiotics to intermittent $\beta$-lactam antibiotics as treatment for hospitalized patients with infections, and (3) it was conducted in humans. Trials focusing on pharmacokinetic or pharmacodynamic parameters with no description of clinical outcomes were excluded. Cross-over RCTs were excluded given concern that this intervention would obscure the benefit of either method of $\beta$-lactam administration. Standardized data abstraction forms and risk of bias forms were completed for all included studies.

\section{Data extraction}

Data were extracted by two independent reviewers. Any disagreement was resolved by consensus with the remaining reviewers. The following data were abstracted from each study: study setting and time period, patient ages, baseline APACHE II scores, body sites of infection, and responsible pathogens. Antibiotic name, dose, interval, and duration of infusion, as well as use of additional antibiotics were also recorded. Definition of mortality, clinical cure, adverse effects, and number of participants discontinuing therapy were collected. Extracted data were entered into RevMan version 5.0 software (Copenhagen: The Nordic Cochrane Centre, The Cochrane Collaboration, 2008) and a second author independently confirmed accurate data entry into this program. 


\section{Methodological quality}

Two independent reviewers utilized guidelines from the Cochrane Handbook for Systematic Reviews of Interventions to assess manuscript quality [13]. Disagreements were resolved by group consensus. Parameters evaluated included sequence generation, allocation concealment, masking, selective outcome reporting, differential loss to follow-up, and intention-to-treat analysis. The source of the study's funding was also documented. If any of this information could not be determined from study description, "unclear" was documented.

\section{Data analysis and statistical methods}

Statistical analyses were performed using RevMan 5.0 software. After a qualitative assessment of heterogeneity, quantitative heterogeneity was assessed by $\mathrm{Chi}^{-}$square statistics. The extent of the inconsistencies was characterized using the $\mathrm{I}^{2}$ statistic. Considerable heterogeneity was indicated by $\mathrm{I}^{2}>50 \%$ [13]. All outcomes were reported as dichotomous. Pooled relative risks (RR) and 95\% confidence intervals (CI) for mortality and clinical cure were calculated by use of the Mantel-Haenszel random-effects model given the heterogeneity observed between studies. Publication bias was assessed using funnel plots on mortality and clinical cure endpoints. Sensitivity analyses were performed to test our assumption that inclusion of studies without strict intention-totreat analysis did not significantly alter results compared to exclusion of these studies. Planned sub-group analyses included the following: continuous infusion $\beta$-lactams (excluding extended infusion), $\beta$-lactam subclasses, exclusion of pharmaceutical industry funded trials, infections with MDRGNs, and restriction to studies with equivalent total daily dose of $\beta$-lactams in both arms. For all analyses, a p-value $<0.05$ was regarded as statistically significant.

\section{Results}

\section{Study selection}

We identified 3181 potentially relevant published articles on review of MEDLINE $(\mathrm{n}=1884)$, EMBASE $(\mathrm{n}=$ 894), and CENTRAL ( $\mathrm{n}=403$ ) (Figure 1). After removing 181 duplicates, 3000 titles and abstracts were reviewed by two independent study team members. Forty-four studies underwent full text review and 13 met criteria for inclusion. After review of Web of Science and hand searching the citation list of each included study, 1 additional study was included [14]. The baseline characteristics of the 14 included studies are described in Table $1[3,4,9,11,14-23]$.

\section{Study characteristics}

Study sample sizes varied from 10 to 531 patients. Studies were conducted on at least 4 continents, with the majority in North America or Europe. Year of publication ranged from 1979 to 2008, with all but two studies published after the year 2000 [15,19]. Patients were admitted to the intensive care unit for all or part of their admission in half of the included studies $[4,11,16,20,21]$.

Extended infusion $\beta$-lactams were administered in the experimental arm in 3 studies, with the infusion time ranging from 3-7 hours $[14,18,21]$. The remaining studies included patients receiving continuous infusion $\beta$-lactams $[3,4,9,11,15-17,19,20,22,23]$. Six studies used the same total daily dose of $\beta$-lactams in both study arms [9,15,17-20]. Table 2 describes the antibiotic dose and infusion schedules in each study. In all studies utilizing a continuous infusion mechanism of $\beta$-lactam delivery, a loading dose of the $\beta$-lactam was initially administered to ensure early attainment of $\mathrm{fT}>\mathrm{MIC}$. Patients received additional non- $\beta$-lactam antibiotics in 11 studies $[4,9,11,14-17,19,21,22]$. The medication in the study arms differed in one trial in which doripenem was compared to imipenem [21]. Because of the similar spectrum of activity of these agents, this study was included. Duration of therapy varied markedly between studies with a mean of 9.4 days. In several studies, $\beta$-lactam dosing was adjusted for renal insufficiency $[4,11,16,20,24]$.

\section{Risk of bias within studies}

In general, there were few methodologically sound studies with adequate sample sizes to definitively determine whether prolonged infusion $\beta$-lactams are superior to intermittent infusion $\beta$-lactams for the treatment of infections in hospitalized patients. As outlined in Table 3 , all included studies were RCTs but the method of randomization was detailed in only three trials $[9,11,15]$. Inclusion and exclusion criteria were clearly defined in all trials. All studies included participants $\geq 18$ years of age, although Angus et al and Hanes et al had younger age limits of 14 years and 16 years, respectively $[3,4]$. Allocation concealment was implemented in only two studies, as seen in Table 2[9,15]. The remaining studies largely failed to address allocation concealment. Masking was conducted in only one study [9]. Intention-to-treat analysis was conducted in eight studies $[9,15-19,21,22]$. A sensitivity analysis was conducted including only those studies that clearly indicated intention-to-treat analysis to investigate the impact of decreasing methodological quality among studies on our pooled RRs. The quantitative summary measure of effect remained largely unchanged, suggesting that our results were not disproportionately influenced by inclusion of studies not utilizing intention-to-treat analyses (Table 4).

A pharmaceutical company was identified as the source of funding for nine trials [3,11,14-16,19-21,23]. Funnel plots comparing prolonged infusion and 


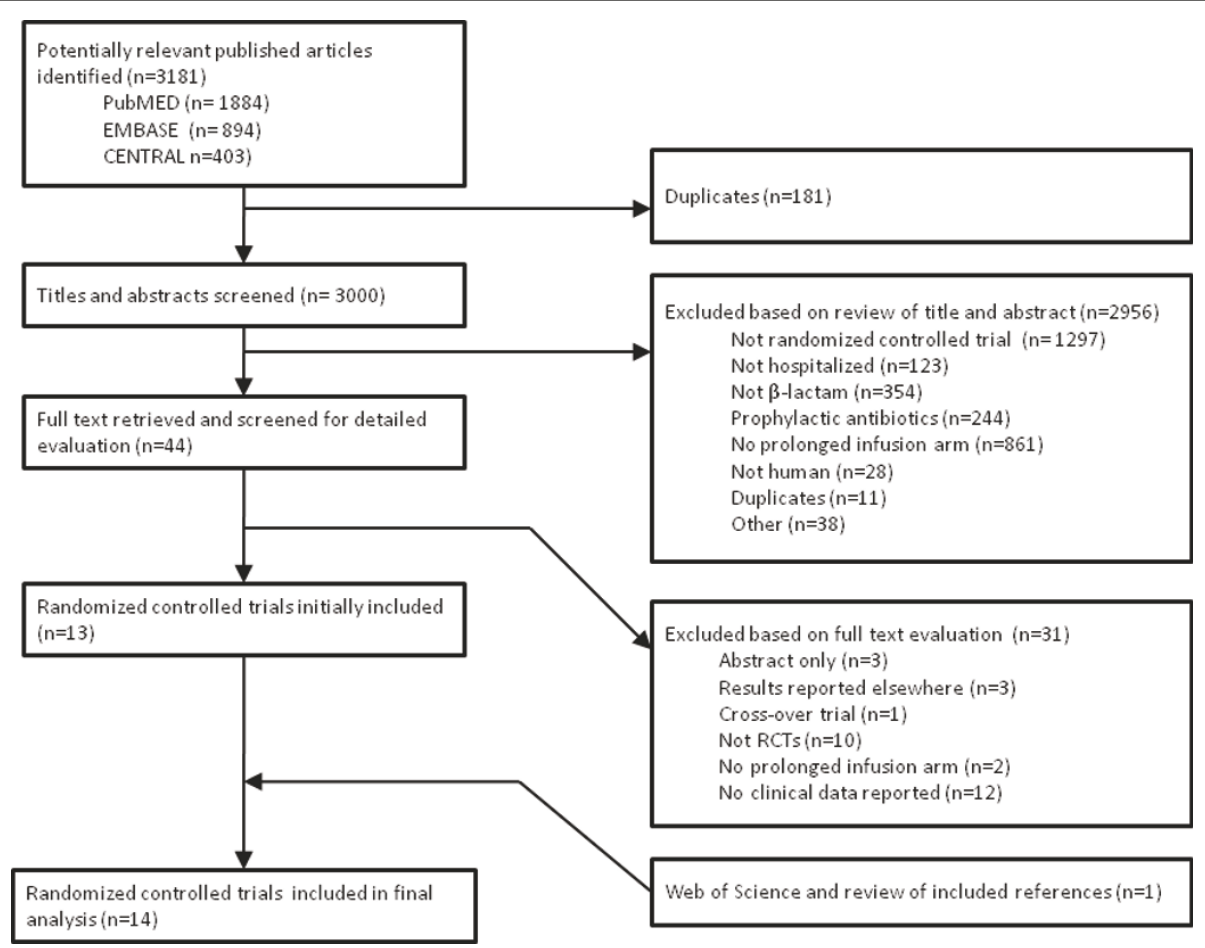

Figure 1 Flow diagram of selection of articles for inclusion in meta-analysis of randomized controlled trials comparing clinical outcomes of prolonged infusion and intermittent infusion of $\beta$-lactams in hospitalized inpatients.

intermittent infusion $\beta$-lactams were performed to screen for evidence of publication bias for the mortality and clinical cure outcomes (Figure 2). For the mortality outcome, the plot suggested a paucity of studies indicating a protective effect of prolonged $\beta$-lactam infusion of mortality. A funnel plot evaluating the outcome of clinical cure, however, was relatively symmetrical, suggesting minimal publication bias. Overall, based on qualitative and quantitative exploration, no conclusive evidence of reporting bias was found.

\section{Mortality}

Eight studies reported mortality as an outcome (Figure 3). Among the 487 patients enrolled in the prolonged infusion $\beta$-lactam arm, there were 53 deaths, compared to 56 deaths among the 495 patients in the intermittent infusion arm. These differences were not statistically significant with an RR of 0.92 (95\% CI 0.61 - 1.37). The overall $\mathrm{I}^{2}$ statistic was $9 \%$ suggesting relatively low heterogeneity between the studies. Similarly, the Chi-square statistic was $7.66, \mathrm{p}=0.36$. All studies except one crossed the null value [4]. Mortality ranged from $2 \%$ in a trial consisting of a relatively young population with low severity of illness to $57 \%$ in a severely ill population infected with a highly pathogenic organism, Burkholderia pseudomallei $[4,20]$. Only one study demonstrated a mortality advantage to prolonged infusion $\beta$-lactams [4]. This was the only study in which all included subjects were in critical condition and had bacterial cultures confirming infection with a resistant Gram-negative organism.

Because of an a priori hypothesis that certain $\beta$-lactams may be more effective with prolonged infusion mechanisms than others, subgroup analysis of each of the $\beta$-lactam subclasses was conducted. This hypothesis was based on the observation that some $\beta$-lactams, like piperacillin, have a MIC breakpoint higher than postulated to be effective based on Monte Carlo simulation techniques [8]. No significant differences were found between subclasses, although each of these subgroups was relatively small. Similarly, subgroup analyses including only studies that used continuous infusion $\beta$-lactams, only non-pharmaceutical industry sponsored trials, and only studies utilizing equivalent total daily $\beta$-lactam dose in both study arms did not yield results different from the pooled RR derived from inclusion of all studies (Table 4). A subgroup analysis was planned for studies with highly resistant organisms, but the MIC for organisms was not reported in the vast majority of trials, precluding completion of this subgroup analysis.

\section{Clinical cure}

All but one study included clinical cure as an outcome (Figure 4) [4]. Proportion of clinical cure ranged from $32 \%$ to $100 \%$. In the prolonged arm, 470 out of 677 
Table 1 Characteristics of eligible studies included in a meta-analysis of prolonged infusion versus intermittent infusion of $\beta$-lactams in hospitalized patients

\begin{tabular}{|c|c|c|c|c|c|c|c|}
\hline Study & Country & Setting & $\begin{array}{l}\text { Sample } \\
\text { Size }\end{array}$ & Type of Infection & $\begin{array}{l}\text { Mean Age } \\
\text { (range) }\end{array}$ & $\begin{array}{l}\text { Mean } \\
\text { APACHE II } \\
\text { Score } \\
\text { (range) }\end{array}$ & Definition of Clinical Cure \\
\hline $\begin{array}{l}\text { Angus } \\
2000\end{array}$ & Thailand & $\begin{array}{l}\text { Not } \\
\text { specified }\end{array}$ & 21 & $\begin{array}{l}\text { Septicemia, } \\
\text { meliodosis }\end{array}$ & NA $(27-73)$ & NA (3-27) & Not specified \\
\hline $\begin{array}{l}\text { Bodey } \\
1979\end{array}$ & USA & Non-ICU & 204 & $\begin{array}{l}\text { Bacteremia, } \\
\text { pneumonia, UTI†, } \\
\text { neutropenic Fever }\end{array}$ & $\begin{array}{l}\text { Not } \\
\text { specified }\end{array}$ & $\begin{array}{l}\text { Not } \\
\text { specified }\end{array}$ & $\begin{array}{l}\text { Disappearance of all clinical and laboratory evidence } \\
\text { of infection at the time administration of antibiotics } \\
\text { was discontinued }\end{array}$ \\
\hline Buck 2005 & Germany & Non-ICU & 24 & Various & $60.3(32-88)$ & $\begin{array}{l}\text { Not } \\
\text { specified }\end{array}$ & $\begin{array}{l}\text { Improvement of clinical and laboratory signs of } \\
\text { infection: resolution of fever, decreased CRP, } \\
\text { normalized leukocytes, CXR resolution }\end{array}$ \\
\hline $\begin{array}{l}\text { Georges } \\
2005\end{array}$ & France & $\mathrm{ICU}$ & 50 & $\begin{array}{l}\text { Pneumonia, } \\
\text { bacteremia }\end{array}$ & 48.0 & $\begin{array}{l}\text { Not } \\
\text { specified }\end{array}$ & $\begin{array}{l}\text { Complete resolution of infectious signs without } \\
\text { further need for antibiotics }\end{array}$ \\
\hline $\begin{array}{l}\text { Hanes } \\
2000\end{array}$ & USA & $\mathrm{ICU}$ & 32 & Pneumonia & 34.5 & 11.6 & $\begin{array}{l}\text { Complete resolution of all signs/symptoms of } \\
\text { pneumonia, or improvement in } 1+\text { signs/symptoms } \\
\text { of pneumonia }\end{array}$ \\
\hline $\begin{array}{l}\text { Kojika } \\
2005\end{array}$ & Japan & $\begin{array}{l}\text { Not } \\
\text { specified }\end{array}$ & 10 & $\begin{array}{l}\text { Abdominal } \\
\text { abscesses }\end{array}$ & $63.7(43-85)$ & $12.5(9-21)$ & Afebrile and normalized white blood cell count \\
\hline $\begin{array}{l}\text { Lagast } \\
1983\end{array}$ & Belgium & $\begin{array}{l}\text { Not } \\
\text { specified }\end{array}$ & 45 & Septicemia & $\begin{array}{l}\text { Not } \\
\text { specified }\end{array}$ & $\begin{array}{l}\text { Not } \\
\text { specified }\end{array}$ & $\begin{array}{l}\text { Disappearance of all clinical and laboratory evidence } \\
\text { of infection }\end{array}$ \\
\hline Lau 2006 & USA & $\mathrm{ICU}$ & 262 & $\begin{array}{l}\text { Abdominal } \\
\text { infections }\end{array}$ & $49.8(18-95)$ & $7.9(0-31)$ & $\begin{array}{l}\text { Complete resolution of clinical signs and symptoms } \\
\text { or improvement (reduction of majority of signs and } \\
\text { symptoms and no new signs of infection) }\end{array}$ \\
\hline $\begin{array}{l}\text { Lubasch } \\
2003\end{array}$ & Germany & $\begin{array}{l}\text { Not } \\
\text { specified }\end{array}$ & 81 & $\begin{array}{l}\text { COPD+† } \\
\text { exacerbations }\end{array}$ & 65.3 & $\begin{array}{l}\text { Not } \\
\text { specified }\end{array}$ & Recurrence to situation before exacerbation \\
\hline $\begin{array}{l}\text { Merchant } \\
2008\end{array}$ & $\begin{array}{l}\text { USA, } \\
\text { Europe }\end{array}$ & $\mathrm{ICU}$ & 531 & Pneumonia & 51.5 & NA (8-29) & Microbiologic and clinical response \\
\hline $\begin{array}{l}\text { Nicolau } \\
2001\end{array}$ & USA & $\mathrm{ICU}$ & 41 & $\begin{array}{l}\text { Pneumonia, } \\
\text { bacteremia }\end{array}$ & 51.1 & 14.7 & $\begin{array}{l}\text { Complete resolution of pneumonia or lack of } \\
\text { progression of abnormalities on chest radiograph }\end{array}$ \\
\hline $\begin{array}{l}\text { Rafati } \\
2006\end{array}$ & Iran & $\mathrm{ICU}$ & 40 & $\begin{array}{l}\text { Pneumonia, } \\
\text { bacteremia, UTIs, } \\
\text { SSI, abdominal } \\
\text { infections }\end{array}$ & 49 & 15.3 & $\begin{array}{l}\text { Change in APACHE II score, afebrile, normalization of } \\
\text { WBC }\end{array}$ \\
\hline $\begin{array}{l}\text { Roberts } \\
2007\end{array}$ & Australia & $\mathrm{ICU}$ & 57 & Septicemia & 47.4 & 17.6 & $\begin{array}{l}\text { Disappearance of all signs and symptoms related to } \\
\text { the infection }\end{array}$ \\
\hline $\begin{array}{l}\text { Van } \\
\text { Zanten } \\
2006\end{array}$ & $\begin{array}{l}\text { Netherlan } \\
\text { ds }\end{array}$ & $\begin{array}{l}\text { Not } \\
\text { specified }\end{array}$ & 93 & $\begin{array}{l}\text { COPD } \\
\text { exacerbations }\end{array}$ & $66.0(34-76)$ & $\begin{array}{l}\text { Not } \\
\text { specified }\end{array}$ & $\begin{array}{l}\text { Infiltrate improvement on x-ray, clinical improvement, } \\
\text { and no need for antibiotic treatment within } 48 \mathrm{~h} \\
\text { after cefotaxime discontinuation }\end{array}$ \\
\hline
\end{tabular}

+Urinary tract infection; †tchronic obstructive pulmonary disease.

evaluable patients were considered clinical successes. This compared to 479 out of 703 in the standard infusion arm. The pooled RR was 1.00 (95\% CI 0.94-1.06). The $\mathrm{I}^{2}$ statistic was $0 \%$, and similarly the Chi-square statistic did not indicate heterogeneity $(p=0.58)$. Similar to mortality, no significant difference was observed in clinical success between prolonged infusion and intermittent infusion $\beta$-lactam antibiotics. Only one study demonstrated a statistically significant clinical cure outcome, favoring the prolonged infusion arm [9]. Of importance, this was the only study in which the allocation sequence was adequately generated, allocation concealment was appropriate, some degree of blinding occurred, and appropriate intention to treat analysis was utilized. Subgroups for clinical cure were analyzed in the same manner as mortality, with results that were similar to pooled estimates as displayed in Table 4.

\section{Adverse effects}

Six studies reported adverse effects during administration of the study medication. The most common reported adverse effects were diarrhea and hepatotoxicity. For almost all studies, the inclusion criteria for adverse effects were not developed a priori. The definition of adverse effects varied substantially between studies preventing calculation of a meaningful pooled RR ratio (Figure 5).

\section{Study withdrawals}

Differential losses to follow-up appeared to be minimal, as rates of study withdrawals were relatively similar 


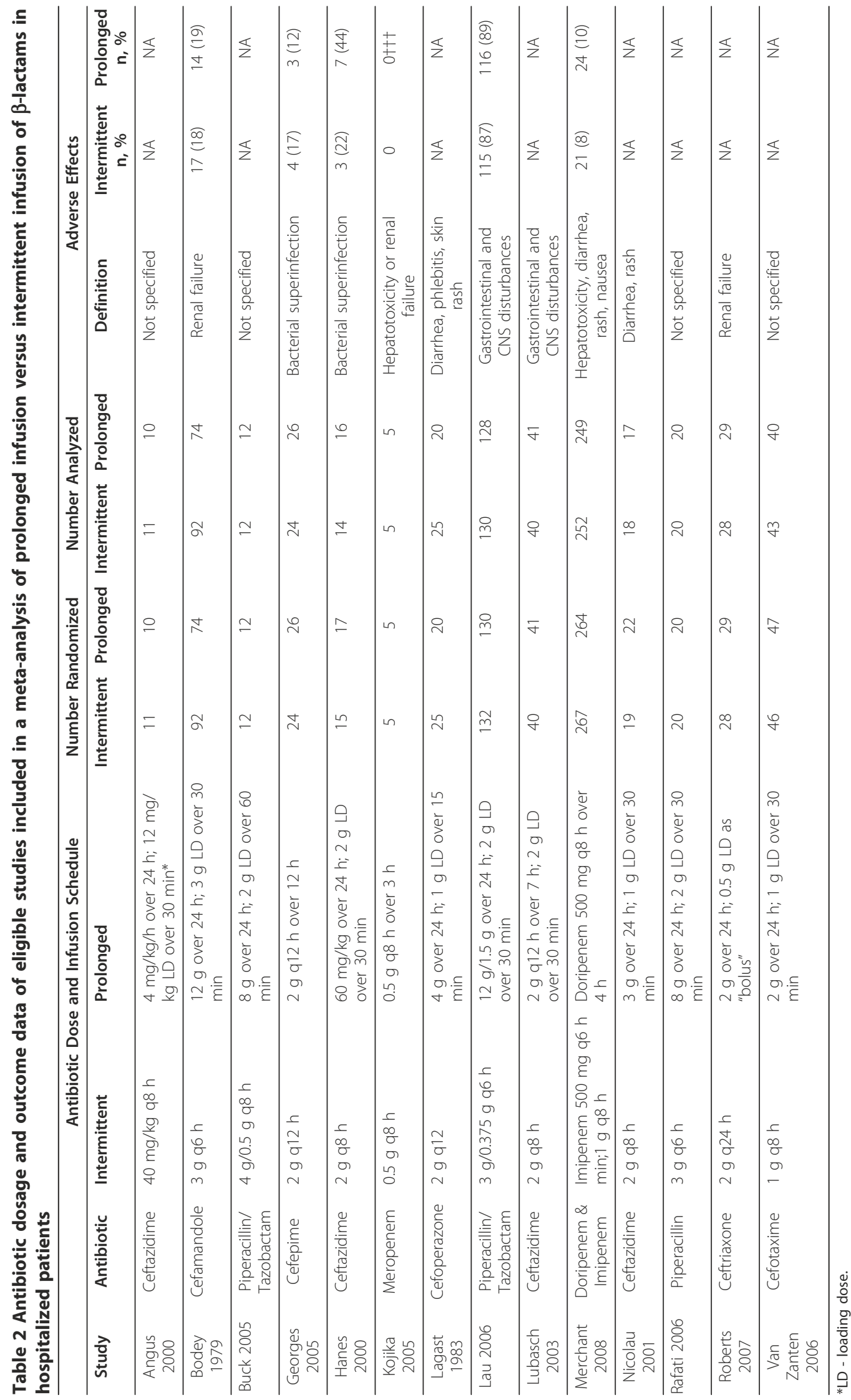


Table 3 Risk of bias assessment of eligible studies included in a meta-analysis of prolonged infusion versus intermittent infusion of $\beta$-lactams in hospitalized patients

\begin{tabular}{|c|c|c|c|c|c|c|}
\hline Study & Funding Source & $\begin{array}{l}\text { Allocation Sequence } \\
\text { Adequately Generated }\end{array}$ & $\begin{array}{l}\text { Allocation } \\
\text { Concealment }\end{array}$ & Masking & $\begin{array}{l}\text { Similar Rates of } \\
\text { Withdrawals Between } \\
\text { Groups }\end{array}$ & $\begin{array}{l}\text { Intention to } \\
\text { Treat Analysis }\end{array}$ \\
\hline $\begin{array}{l}\text { Angus } \\
2000\end{array}$ & $\begin{array}{l}\text { Wellcome Trust of Great } \\
\text { Britain }\end{array}$ & Unclear & Unclear & Unclear & Yes & No \\
\hline $\begin{array}{l}\text { Bodey } \\
1979\end{array}$ & Pharmaceutical company & Yes & Yes & Unclear & Unclear & Yes \\
\hline Buck 2005 & Pharmaceutical company & Unclear & Unclear & No & Yes & Yes \\
\hline $\begin{array}{l}\text { Georges } \\
2005\end{array}$ & Not specified & Unclear & Unclear & No & Yes & Yes \\
\hline $\begin{array}{l}\text { Hanes } \\
2000\end{array}$ & Pharmaceutical company & Unclear & Unclear & Unclear & Yes & No \\
\hline $\begin{array}{l}\text { Kojika } \\
2005\end{array}$ & Not specified & Unclear & No & No & Yes & Yes \\
\hline $\begin{array}{l}\text { Lagast } \\
1983\end{array}$ & Pharmaceutical company & Unclear & Unclear & Unclear & Yes & Yes \\
\hline Lau 2006 & Pharmaceutical company & Unclear & Unclear & No & Yes & No \\
\hline $\begin{array}{l}\text { Lubasch } \\
2003\end{array}$ & Pharmaceutical company & Unclear & Unclear & No & Unclear & Unclear \\
\hline $\begin{array}{l}\text { Merchant } \\
2008\end{array}$ & Pharmaceutical company & Unclear & Unclear & No & Yes & Yes \\
\hline $\begin{array}{l}\text { Nicolau } \\
2001\end{array}$ & Pharmaceutical company & Yes & Unclear & No & Yes & No \\
\hline $\begin{array}{l}\text { Rafati } \\
2006\end{array}$ & $\begin{array}{l}\text { Tehran University Medical } \\
\text { Sciences Research Board }\end{array}$ & Unclear & Unclear & No & Yes & Yes \\
\hline $\begin{array}{l}\text { Roberts } \\
2007\end{array}$ & $\begin{array}{l}\text { National Health \& Medical } \\
\text { Research Council }\end{array}$ & Yes & Yes & Yes $^{a}$ & Yes & Yes \\
\hline $\begin{array}{l}\text { Van } \\
\text { Zanten } \\
2006\end{array}$ & Pharmaceutical company & Unclear & Unclear & No & No & No \\
\hline
\end{tabular}

${ }^{\mathrm{a} O n l y}$ outcome assessors were masked.

between study arms (Figure 6). No study reported greater than $12 \%$ study withdrawal. $[3,4,9,16-22,24]$ Because of the scarcity of details regarding reasons for withdrawals, a summary statistic for withdrawals was not calculated.

\section{Discussion}

Several observational studies with varying study designs comparing clinical benefits of prolonged and intermittent infusion of $\beta$-lactam antibiotics have been conducted with inconsistent results. A prospective study of

Table 4 Summary of subgroup and sensitivity analysis of eligible studies included in a meta-analysis of prolonged infusion versus intermittent infusion of $\beta$-lactams in hospitalized patientst

\begin{tabular}{|c|c|c|c|c|c|c|}
\hline Sub-group analysis & $\begin{array}{l}\text { Studies } \\
\text { Included }\end{array}$ & $\begin{array}{c}\text { Mortality } \\
\text { Risk Ratio (95\% } \\
\text { Cl) }\end{array}$ & $1^{2} \%$ & $\begin{array}{l}\text { Studies } \\
\text { Included }\end{array}$ & $\begin{array}{c}\text { Clinical Cure } \\
\text { Risk Ratio }(95 \% \\
\text { CI) }\end{array}$ & $I^{2} \%$ \\
\hline \multicolumn{7}{|l|}{$\beta$-lactam subclasses } \\
\hline Penicillins & 2 & $0.62(0.19-2.03)$ & 0 & 3 & $0.77(0.46-1.30)$ & 0 \\
\hline Cephalosporins & 4 & $0.95(0.35-2.63)$ & 50 & 8 & $1.04(0.92-1.18)$ & 35 \\
\hline Carbapenems & 2 & $1.08(0.64-1.82)$ & 0 & 2 & $1.00(0.69-1.44)$ & 0 \\
\hline Continuous infusion & 6 & $0.80(0.42-1.50)$ & 22 & 10 & $1.01(0.92-1.10)$ & 16 \\
\hline Not funded by pharmaceutical industry & 5 & $0.80(0.37-1.73)$ & 26 & 5 & $1.15(0.85-1.57)$ & 57 \\
\hline Equivalent daily dose of $\beta$-lactam antibiotic & 5 & $1.30(0.59-2.87)$ & 0 & 6 & $1.06(0.90-1.25)$ & 48 \\
\hline \multicolumn{7}{|l|}{ Sensitivity-analysis } \\
\hline Intention-to-treat analysis & 8 & $1.10(0.75-1.60)$ & 0 & 8 & $1.05(0.93-1.19)$ & 21 \\
\hline
\end{tabular}

† Reference group is intermittent $\beta$-lactam infusion. 

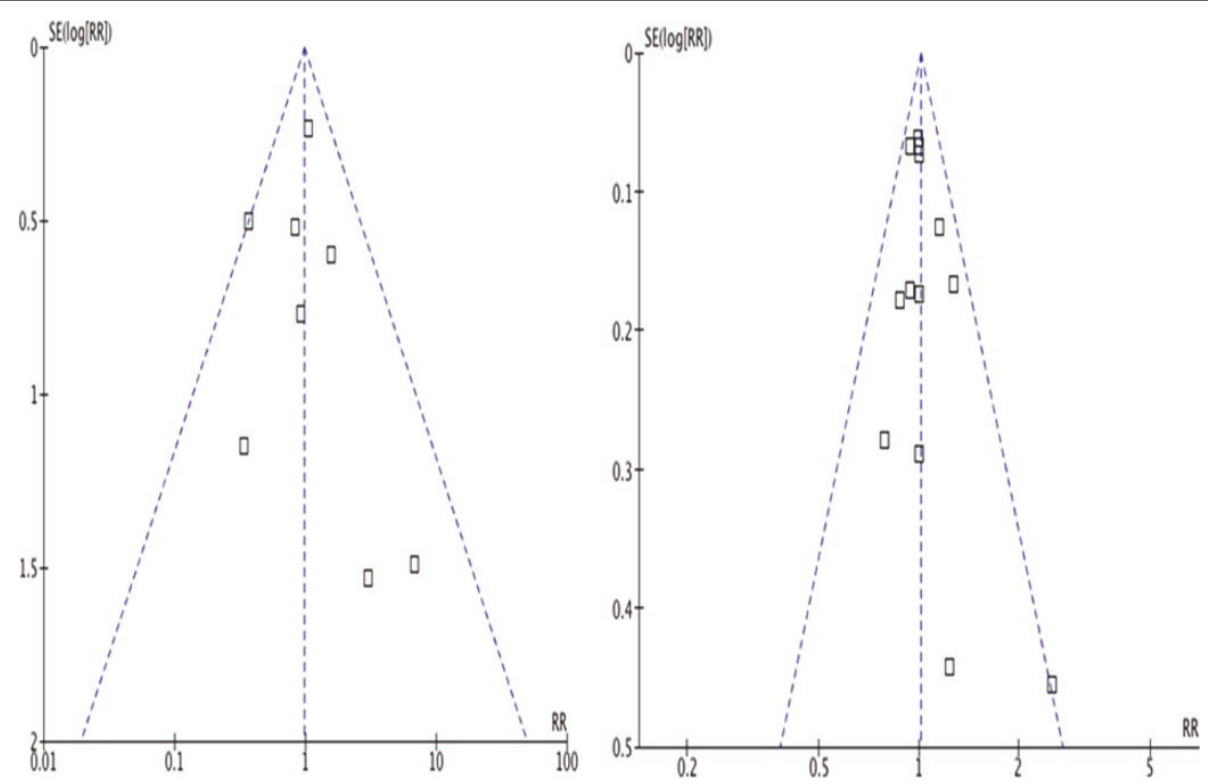

Figure 2 Funnel plots demonstrating the possibility of a small publication bias assessing studies reporting mortality (left) but low probability of publication bias assessing studies reporting clinical cure (right) comparing prolonged and intermittent infusion of $\beta$ lactam antibiotics in hospitalized patients.

98 hospitalized patients who were prescribed piperacillin-tazobactam revealed a trend towards greater clinical success in the continuous infusion group when compared with intermittent infusion recipients [25]. In a retrospective cohort study of piperacillin-tazobactam for Pseudomonas aeruginosa sepsis, a significantly lower 14day mortality rate and shorter hospital length of stay in patients receiving extended infusion, was demonstrated [26]. Results from another retrospective cohort study showed increased clinical cure by continuous versus intermittent infusion of piperacillin-tazobactam in adults with ventilator-associated pneumonia (VAP) caused by Gram-negative pathogens with MICs $\geq 8 \mu \mathrm{g} / \mathrm{ml}$ [27]. A third retrospective cohort study, however, failed to demonstrate improved clinical outcomes with extended infusion piperacillin-tazobactam [28]. Drug-related adverse effects were mild and reported in similar numbers in both treatment arms in all of these studies
[25-28]. Retrospective studies comparing continuous infusion versus intermittent infusion cefepime and meropenem in patients with VAP both noted significantly improved clinical cure rates in the continuous infusion arms [29,30].

In an attempt to clarify the comparative effect of prolonged versus intermittent infusion $\beta$-lactam antibiotics on mortality, clinical cure, and adverse effects, we analyzed RCTs that offered the most methodologically rigorous evidence from the available studies. Our results do not demonstrate a clinical advantage to prolonged infusion $\beta$-lactams for routine use in hospitalized patients. Sensitivity analyses and various sub-group analyses determined by a priori biologically-plausible hypotheses similarly did not indicate an advantage to prolonged infusion $\beta$-lactams.

Two previous systematic reviews and meta-analyses were published to answer similar questions [31,32]. A

\begin{tabular}{|c|c|c|c|c|c|c|c|c|}
\hline Study or Subgroup & \multicolumn{2}{|c|}{ Prolonged } & \multicolumn{2}{|c|}{ Intermittent } & Weight & $\begin{array}{c}\text { Risk Ratio } \\
\text { M-H, Random, } 95 \% \mathrm{CI}\end{array}$ & \multicolumn{2}{|c|}{$\begin{array}{c}\text { Risk Ratio } \\
\mathrm{M}-\mathrm{H}, \text { Random, } 95 \% \mathrm{CI}\end{array}$} \\
\hline Angus 2000 & 3 & 10 & 9 & 11 & $14.6 \%$ & $0.37[0.14,0.98]$ & & \\
\hline Georges 2005 & 3 & 26 & 3 & 24 & $6.7 \%$ & $0.92[0.21,4.14]$ & & \\
\hline Kojika 2005 & 1 & 5 & 0 & 5 & $1.8 \%$ & $3.00[0.15,59.89]$ & & \\
\hline Lagast 1983 & 5 & 20 & 4 & 25 & $10.6 \%$ & $1.56[0.48,5.06]$ & - & \\
\hline Lau 2006 & 1 & 128 & 3 & 130 & $3.1 \%$ & $0.34[0.04,3.21]$ & & \\
\hline Merchant 2008 & 32 & 249 & 31 & 252 & $47.4 \%$ & $1.04[0.66,1.66]$ & & \\
\hline Rafati 2006 & 5 & 20 & 6 & 20 & $13.9 \%$ & $0.83[0.30,2.29]$ & & \\
\hline Roberts 2007 & 3 & 29 & 0 & 28 & $1.9 \%$ & $6.77[0.37,125.32]$ & & \\
\hline Total $(95 \% \mathrm{CI})$ & & 487 & & 495 & $100.0 \%$ & $0.92[0.61,1.37]$ & & \\
\hline Total events & 53 & & 56 & & & & & \\
\hline $\begin{array}{l}\text { Heterogeneity: Tau } \\
\text { Test for overall effec }\end{array}$ & $\begin{array}{l}0.03 ; C h \\
Z=0.43\end{array}$ & $\begin{array}{l}i^{2}=7 \\
(P=0\end{array}$ & $\begin{array}{l}66, d f= \\
.67)\end{array}$ & $7(P=$ & $0.36) ; I^{2}$ & & $\begin{array}{l}0.01 \quad 0.1 \\
\text { Favors Prol }\end{array}$ & $\begin{array}{r}10 \\
\text { Favors Inte }\end{array}$ \\
\hline
\end{tabular}

Figure 3 Mortality comparing prolonged infusion and intermittent infusion of $\beta$-lactam antibiotics in hospitalized patients 


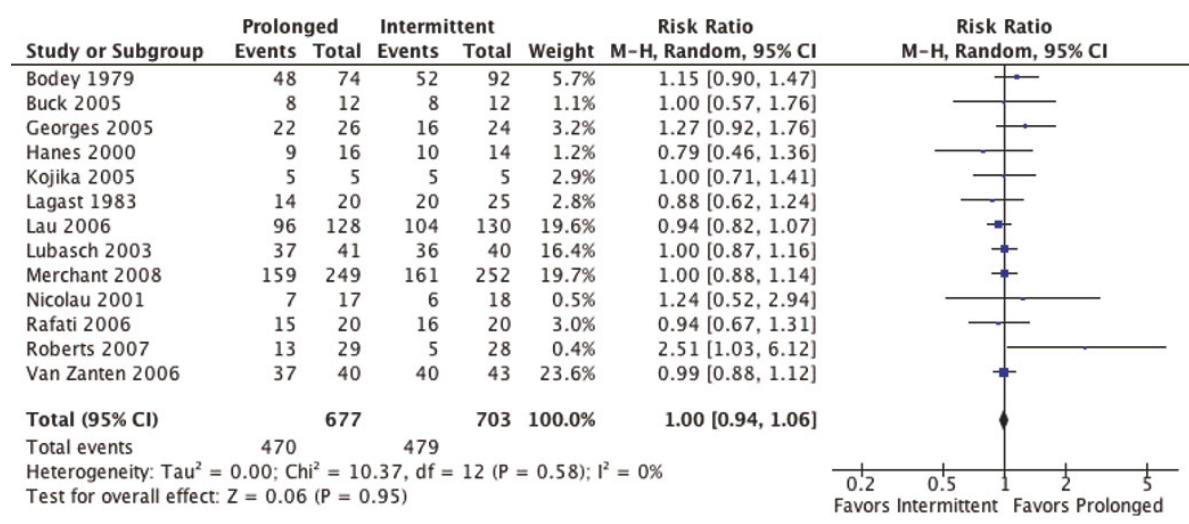

Figure 4 Clinical cure comparing prolonged infusion and intermittent infusion of $\beta$-lactam antibiotics in hospitalized patients

previous meta-analysis included continuous infusion of aminoglycosides and vancomycin, making it difficult to isolate the benefit of $\beta$-lactams [32]. A prior systematic review focused on continuous infusion $\beta$-lactams in the prolonged arm and included cross-over studies [31]. In vitro evidence demonstrates similar properties of $\mathrm{fT}>\mathrm{MIC}$ for both extended and continuous infusion $\beta$ lactams making their effect likely comparable, thus we elected to include both groups under the umbrella term "prolonged infusion," a decision that was further supported by our sub-group analysis of only studies examining continuous $\beta$-lactam infusions. Inclusion of crossover studies obscures clinical benefits attributable to the different infusion schedules, and therefore these studies were excluded in the present review. The current metaanalysis includes two additional RCTs, consisting of 612 patients, compared with those published previously $[14,21]$. Overall, the findings of our meta-analysis are consistent with those previously described [31,32].

Our study has several limitations that should be taken into account when interpreting the results. Overall, the included studies were of moderate to poor quality with regards to answering our clinical question of interest and had notable methodological differences. Allocation sequence generation and allocation concealment were not addressed in most studies. As a result, most of these studies were at risk for selection bias. Similarly, most of the studies did not adequately address masking, making detection bias a consideration. Although masking of health care providers and patients may be difficult to impose because of the nature of the intervention, masking of outcome assessors would certainly be reasonable. Of interest, the study with the most stringent methods was the only one to show a clinical cure advantage for prolonging $\beta$-lactam infusions [9]. Most trials were funded by the pharmaceutical industry, making reporting bias a concern. Studies conducted by the pharmaceutical industry with unfavorable results for prolonged infusion $\beta$-lactams may be less likely to be published [33].

Another noteworthy limitation is that participants in the available studies were frequently receiving additional antibiotics, generally aminoglycosides, limiting conclusions about the sole contribution of the $\beta$-lactam antibiotics. In reality, however, when prolonged $\beta$-lactams are administered, it is generally a final attempt to rid the body of a particular pathogen and is administered in conjunction with aminoglycoside therapy, making the design of several of these studies similar to actual clinical practice [7]. Only six of the studies used the same total daily dose of $\beta$-lactam antibiotic in both arms $[8,9,15,17-19]$. The majority of studies used a higher dose of antibiotic in the intermittent infusion arm and this unequal treatment favoring standard infusions could have biased the results towards the null. Subgroup analysis of studies with equivalent total daily dose of $\beta$ -

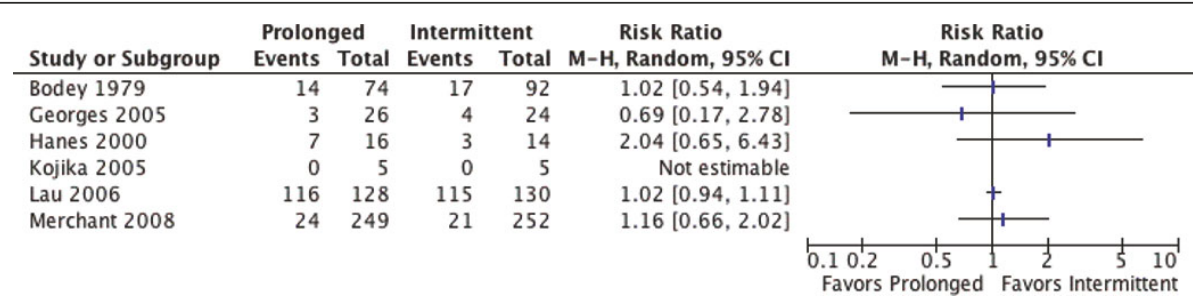

Figure 5 Adverse effects comparing prolonged and intermittent infusion of $\beta$-lactam antibiotics in hospitalized patients. 


\begin{tabular}{|c|c|c|c|c|c|c|c|c|}
\hline Study or Subgroup & \multicolumn{2}{|c|}{ Prolonged } & \multicolumn{2}{|c|}{ Intermittent } & $\begin{array}{c}\text { Risk Ratio } \\
\text { M-H, Random, } 95 \% \text { Cl }\end{array}$ & \multicolumn{3}{|c|}{$\begin{array}{c}\text { Risk Ratio } \\
\text { M-H, Random, } 95 \% \mathrm{Cl}\end{array}$} \\
\hline Georges 2005 & 2 & 26 & 1 & 24 & $1.85[0.18,19.08]$ & & & 1 \\
\hline Hanes 2000 & 1 & 16 & 1 & 14 & $0.88[0.06,12.73]$ & & & \\
\hline Kojika 2005 & 0 & 5 & 0 & 5 & Not estimable & & & \\
\hline Lau 2006 & 6 & 128 & 3 & 130 & $2.03[0.52,7.95]$ & & & + \\
\hline Merchant 2008 & 5 & 249 & 3 & 252 & $1.69[0.41,6.98]$ & & & + \\
\hline Roberts 2007 & 4 & 29 & 3 & 28 & $1.29[0.32,5.24]$ & & & + \\
\hline \multirow[t]{2}{*}{ Van Zanten 2006} & 7 & 40 & 3 & 43 & $2.51[0.70,9.04]$ & & & 1 \\
\hline & & & & & & $\begin{array}{l}0.01 \\
\text { Favors }\end{array}$ & $\begin{array}{l}0.1 \\
s \text { Prolonged }\end{array}$ & $\begin{array}{l}10 \\
\text { Favors Inter }\end{array}$ \\
\hline
\end{tabular}

Figure 6 Study participant withdrawals comparing prolonged and intermittent infusion of $\beta$-lactam antibiotics in hospitalized patients.

lactam antibiotic in both arms was conducted and did not demonstrate any significant results; however, interpretation of these results is limited by the relatively small sample size of this population and the notable heterogeneity of these trials $\left(\mathrm{I}^{2}=50 \%\right)$.

Perhaps the biggest limitation to our study is that the bacterial isolates identified in the included RCTs generally had MICs in the susceptible range. Little difference exists between intermittent and prolonged administration of $\beta$-lactams in achieving $\mathrm{fT}>\mathrm{MIC}$ in this range of susceptibility [2]. However, when less susceptible organisms are present, the likelihood for treatment failure increases with intermittent dosing. In one study, maintaining a fT $>$ MIC of $100 \%$ for cephalosporins was associated with significantly improved clinical cure compared to maintenance of $\mathrm{fT}>\mathrm{MIC}$ at lower percentages [34]. Prolonged infusion therapy is generally considered in clinical scenarios involving MDRGN organisms with elevated MICs. From the available RCTs, it cannot be determined if prolonged infusion $\beta$ lactams result in greater clinical success than standard $\beta$-lactam infusions when MDRGNs are the offending pathogens. Interestingly, the one study conducted in critically ill patients with microbiological evidence of a resistant Gram-negative organism did in fact show a mortality benefit in favor of prolonged $\beta$-lactam administration [4]. Perhaps, inclusion of studies with a low burden of disease and highly susceptible microorganisms in our review may have diluted the true effect of prolonged antibiotic infusion regimens.

Despite these limitations, this systematic review and meta-analysis add useful information to the literature. The 14 included studies span 4 continents and are not restricted to the English language, thus increasing generalizability. As only RCTs were included, baseline characteristics including age, severity of illness, body site of infection, responsible pathogens, and underlying medical conditions were similar between the treatment groups. Confounding by indication can be extremely problematic in observational studies, as prognostic factors may influence treatment decisions. However, this was unlikely in the included trials because of the process of randomization.
Optimizing the pharmacokinetics-pharmacodynamics of currently available antibiotics is necessary in the era of MDRGN infections. Known $\beta$-lactam pharmacodynamics support the concept of prolonged infusion to maximize $\mathrm{fT}>\mathrm{MIC}$, but limited clinical data exist regarding the comparative efficacy of prolonged $\beta$-lactam infusion. The results of this meta-analysis do not support an advantage to the use of prolonged infusion $\beta$-lactam antibiotics as standard practice for hospitalized patients. These findings remained consistent in the multiple sensitivity and subgroup analyses that were evaluated.

\section{Conclusions}

Prolonged infusion $\beta$-lactam antibiotics may have value in a specific subsets of patients, such as those with highly-resistant Gram-negative infections because of exploitation of their property of $\mathrm{fT}>\mathrm{MIC}$. Unfortunately, the very limited number of patients in the included RCTs with MDRGNs precluded evaluation of this subgroup in the present meta-analysis. Methodologically rigorous studies analyzing prolonged infusion $\beta$-lactams for critically ill patients with MDRGN infections are necessary to substantiate this potential benefit.

\section{Endnotes}

APPENDIX: Final Electronic Search Strategy (February 11, 2011)

\section{MEDLINE Search Strategy}

(("beta-lactams"[MeSH] OR "beta-lactams"[tiab] OR "beta lactam"[tiab]) AND ("anti-bacterial agents"[MeSH] OR ("anti-bacterial"[tiab] AND "agents"[tiab]) OR "anti-bacterial agents"[tiab] OR "antibiotics"[tiab] OR "antibiotic"[tiab]) OR "beta-lactam antibiotics"[tiab] OR "beta-lactam antibiotic"[tiab] OR doripenem[Title/Abstract] OR cefepime[Title/Abstract] OR ceftazidime[Title/Abstract] OR piperacillin[Title/Abstract] OR piperacillin/tazobactam [tiab] OR piperacillin-tazobactam[tiab] OR cefamandole [tiab] OR cefazolin[tiab] OR cefotaxime[tiab] OR ceftriaxone[tiab] OR imipenem[tiab] OR meropenem[tiab] OR ertapenem[tiab] OR cefoperazone[tiab] OR penicillin [tiab] OR penicillins[tiab] OR imipenem-cilastatin[tiab] OR ampicillin[tiab] OR ampicillin-sulbactam[tiab] OR 
sulbactam-ampicillin[tiab] OR tazocin[tiab] OR carbenicillin[tiab] OR carbapenem[tiab] OR cephalosporin[tiab] OR cephalosporins[tiab] OR ticarcillin-clavulanate[tiab] OR cefpirome[tiab] OR flucloxacillin[tiab] OR mezlocillin[tiab] OR aztreonam[tiab] OR cefuroxime[tiab] OR ceftizoxime[tiab])

\section{AND}

("Drug Administration Schedule"[Mesh] OR "Infusions, Intravenous"[MeSH] OR "continuous infusion"[Title/Abstract] OR "extended infusion"[Title/Abstract] OR "intermittent therapy"[Title/Abstract] OR ((continuous [tiab] OR bolus[tiab] OR extended[tiab] OR intermittent [tiab]) AND (administration[tiab] OR infusion[tiab] OR dosing[tiab])))

\section{AND}

("hospitalized"[tiab] OR "hospitalised"[tiab] OR "hospitalization"[tiab] OR "hospitalisation"[tiab] OR "Bacterial Infections"[Mesh] OR "sepsis"[Title/Abstract] OR (("intensive"[tiab] OR "critical"[tiab] OR "acute"[tiab]) AND ("care"[tiab] OR "unit"[tiab] OR "illness"[tiab])))

\section{AND}

(randomized controlled trial[pt] OR controlled clinical trial[pt] OR randomized[tiab] OR placebo[tiab] OR drug therapy[sh] OR randomly[tiab] OR trial[tiab] OR groups [tiab] NOT (animals[mh] NOT humans[mh]))

\section{Cochrane Search Strategy}

(("beta-lactams"[MeSH] OR "beta-lactams"[all fields] OR "beta lactam"[all fields]) AND ("anti-bacterial agents"[$\mathrm{MeSH}$ ] OR ("anti-bacterial"[all fields] AND "agents"[all fields]) OR "anti-bacterial agents"[all fields] OR "antibiotics"[all fields] OR "antibiotic"[all fields]) OR "beta-lactam antibiotics"[tiab] OR "beta-lactam antibiotic"[tiab] OR doripenem[Title/Abstract] OR cefepime[Title/Abstract] OR ceftazidime[Title/Abstract] OR piperacillin[Title/ Abstract] OR piperacillin/tazobactam[tiab] OR piperacillin-tazobactam[tiab] OR cefamandole[tiab] OR cefazolin [tiab] OR cefotaxime[tiab] OR ceftriaxone[tiab] OR imipenem[tiab] OR meropenem[tiab] OR ertapenem[tiab] OR cefoperazone[tiab] OR penicillin[tiab] OR penicillins [tiab] OR imipenem-cilastatin[tiab] OR ampicillin[tiab] OR ampicillin-sulbactam[tiab] OR sulbactam-ampicillin [tiab] OR tazocin[tiab] OR carbenicillin[tiab] OR carbapenem[tiab] OR cephalosporin[tiab] OR cephalosporins [tiab] OR ticarcillin-clavulanate[tiab] OR cefpirome[tiab] OR flucloxacillin[tiab] OR mezlocillin[tiab] OR aztreonam[tiab] OR cefuroxime[tiab] OR ceftizoxime[tiab])
("Drug Administration Schedule"[Mesh] OR "Infusions, Intravenous"[MeSH] OR "continuous infusion"[Title/Abstract] OR "extended infusion"[Title/Abstract] OR "intermittent therapy"[Title/Abstract] OR ((continuous [tiab] OR bolus[tiab] OR extended[tiab] OR intermittent [tiab]) AND (administration[tiab] OR infusion[tiab] OR dosing[tiab])))

\section{AND}

("inpatient"[mesh] OR "hospitalized"[tiab] OR "hospitalised"[tiab] OR "hospitalization"[tiab] OR "hospitalisation"[tiab] OR "Bacterial Infections"[Mesh] OR "sepsis"[Title/Abstract] OR (("intensive"[tiab] OR "critical"[tiab] OR "acute"[tiab]) AND ("care"[tiab] OR "unit"[tiab] OR "illness"[tiab])))

\section{EMBASE Search Strategy}

('hospital patients':ab,ti OR 'hospitalized patients':ab,ti OR 'hospitalised patients':ab,ti OR 'hospital infection'/ exp OR ('sepsis':ab,ti) OR ('septicemia':ab,ti) OR ('septic shock':ab,ti) OR ('bacterial infection'/exp) OR ('critically ill patient':ab,ti) OR ('critically ill patients'ab,ti) OR ('critical illness':ab,ti) OR ('systemic inflammatory response syndrome':ab,ti))

\section{AND}

(('beta lactams'/exp) OR 'doripenem':ab,ti OR 'cefepime': ab,ti OR 'ceftazidime':ab,ti OR 'piperacillin':ab,ti OR 'piperacillin tazobactam':ab,ti OR 'piperacillin':ab,ti OR 'piperacillin tazobactam combination product':ab,ti OR 'tazobactam':ab,ti OR 'cefamandole':ab,ti OR 'cefazolin':ab, ti OR 'cefotaxime':ab,ti OR 'ceftriaxone':ab,ti OR 'imipenem':ab,ti OR 'meropenem':ab,ti OR 'ertapenem':ab,ti OR 'cefoperazone':ab,ti OR 'penicillin':ab,ti OR 'penicillins':ab, ti OR 'imipenem-cilastatin':ab,ti OR 'ampicillin':ab,ti OR 'ampicillin-sulbactam':ab,ti OR 'sulbactam-ampicillin':ab,ti OR 'tazocin':ab,ti OR 'carbenicillin':ab,ti OR 'carbapenem' ab,ti OR 'cephalosporin':ab,ti OR 'cephalosporins':ab,ti OR 'ticarcillin-clavulanate':ab,ti OR 'cefpirome':ab,ti OR 'flucloxacillin':ab,ti OR 'mezlocillin':ab,ti OR 'aztreonam'ab,ti OR 'cefuroxime':ab,ti OR 'ceftizoxime':ab,ti)

\section{AND}

('drug administration'/exp OR 'intravenous drug administration'/exp OR 'drug intermittent therapy'/exp OR ('continuous infusion':ab,ti) OR ('extended infusion': ab,ti) OR 'intermittent therapy':ab,ti OR (('continuous': ab,ti OR 'bolus':ab,ti OR 'extended':ab,ti OR 'intermittent':ab,ti) AND ('administration':ab,ti OR 'infusion':ab,ti OR 'dosing':ab,ti))) 


\author{
((('randomized controlled trial'/exp OR 'clinical trial'/ \\ exp) OR ('randomization'/exp)))
}

\author{
AND \\ [humans]/lim \\ AND

\section{NOT ('review'/exp OR review)}

\section{Acknowledgements and Funding}

The authors would like to thank Swaroop Vedula, Dolly Chang, Tianjing Li, and Kay Dickersin for all of their guidance and thoughtful suggestions. We would also like to thank our translators - Haruhi and Tsuyoshi Inokuchi (Japanese) and Lila Bouadma and Patrice Savard (French). We appreciate the assistance of the Welch medical librarians in finalizing our search strategy. P.D. T, A.L.R, and K.J.V. are funded by a National Institute of Health 5KL2RR025006 award. None of the authors report any relevant conflicts of interest.

\section{List of abbreviations used}

MDRGNs: multidrug-resistant Gram-negatives; MIC: minimum inhibitory concentration; RCT: randomized controlled trial; CENTRAL: Cochrane Central Register of Controlled Trials; RR: relative risk; Cl: confidence interval; VAP: ventilator-associated pneumonia;

\section{Author details}

'Department of Pediatric Infectious Diseases, Johns Hopkins Medical Institutions, Baltimore, MD, USA. ${ }^{2}$ Department of Pulmonary and Critical Care Medicine, Johns Hopkins Medical Institutions, Baltimore, MD, USA. ${ }^{3}$ Johns Hopkins Medical Institutions, Baltimore, MD, USA. ${ }^{4}$ Department of Surgery, Johns Hopkins Medical Institution, Baltimore, MD, USA. ${ }^{5}$ Department of Pediatrics, Johns Hopkins Medical Institutions, Baltimore, MD, USA.

\section{Authors' contributions}

PDT formulated the research question and was involved in manuscript preparation. All authors were involved in determining the search strategy, data collection for the review, and quantitative and qualitative analysis. All authors read and approved the final manuscript.

\section{Competing interests}

The authors declare that they have no competing interests.

Received: 6 April 2011 Accepted: 22 June 2011 Published: 22 June 2011

\section{References}

1. Rice LB: The clinical consequences of antimicrobial resistance. Curr Opin Microbiol 2009, 12(5):476-81.

2. Drusano GL: Antimicrobial pharmacodynamics: critical interactions of 'bug and drug'. Nat Rev Microbiol 2004, 2(4):289-300.

3. Hanes SD, Wood GC, Herring V, Croce MA, Fabian TC, Pritchard E, Boucher BA: Intermittent and continuous ceftazidime infusion for critically ill trauma patients. Am J Surg 2000, 179(6):436-40.

4. Angus BJ, Smith MD, Suputtamongkol $Y$, Mattie $H$, Walsh AL, Wuthiekanun V, Chaowagul W, White NJ: Pharmacokineticpharmacodynamic evaluation of ceftazidime continuous infusion vs intermittent bolus injection in septicaemic melioidosis. $\mathrm{Br} J \mathrm{Clin}$ Pharmacol 2000, 50(2):184-91.

5. Buijk SL, Gyssens IC, Mouton JW, Van Vliet A, Verbrugh HA, Bruining HA: Pharmacokinetics of ceftazidime in serum and peritoneal exudate during continuous versus intermittent administration to patients with severe intra-abdominal infections. J Antimicrob Chemother 2002, 49(1):121-8.

6. McNabb JJ, Nightingale CH, Quintiliani R, Nicolau DP: Cost-effectiveness of ceftazidime by continuous infusion versus intermittent infusion for nosocomial pneumonia. Pharmacotherapy 2001, 21(5):549-55.

7. Tamma PD, Jenh A, Milstone AM: Prolonged B-lactam Infusion for Gramnegative Infections. Pediatr Infect Dis J 2011, 30(4):336-7.

8. Courter JD, Kuti JL, Girotto JE, Nicolau DP: Optimizing bactericidal exposure for beta-lactams using prolonged and continuous infusions in the pediatric population. Pediatr Blood Cancer 2009, 53(3):379-85.

9. Roberts JA, Boots R, Rickard CM, Thomas P, Quinn J, Roberts DM, Richards B, Lipman J: Is continuous infusion ceftriaxone better than oncea-day dosing in intensive care? A randomized controlled pilot study. J Antimicrob Chemother 2007, 59(2):285-91.

10. Sakka SG, Glauner AK, Bulitta JB, Kinzig-Schippers M, Pfister W, Drusano GL, Sorgel F: Population pharmacokinetics and pharmacodynamics of continuous versus short-term infusion of imipenem-cilastatin in critically ill patients in a randomized, controlled trial. Antimicrob Agents Chemother 2007, 51(9):3304-10.

11. Nicolau DP, McNabb J, Lacy MK, Quintiliani R, Nightingale CH: Continuous versus intermittent administration of ceftazidime in intensive care unit patients with nosocomial pneumonia. Int J Antimicrob Agents 2001, 17(6):497-504.

12. Pedebosca S, Dubau B, Frappier S, Hernandez V, Veyssieres D, Winnock S, Pometan JP: [Comparison of 2 administration protocols (continuous or discontinuous) of a time-dependent antibiotic, Tazocin]. Pathol Biol (Paris) 2001, 49(7):540-7.

13. Lefebvre C, Manheimer E, Glanville J: Chapter 6: Searching for studies. In Cochrane Handbook for Systematic Reviews of Interventions Version 5.0.2 (updated September 2009). Edited by: Higgins JPT, Green S. The Cochrane Collaboration; 2009:[http://www.cochrane-handbook.org].

14. Lubasch A, Luck S, Lode H, Mauch H, Lorenz J, Bolcskei P, Welte T: Optimizing ceftazidime pharmacodynamics in patients with acute exacerbation of severe chronic bronchitis. J Antimicrob Chemother 2003, 51(3):659-64.

15. Bodey $G P$, Ketchel $S J$, Rodriguez $\mathrm{V}$ : A randomized study of carbenicillin plus cefamandole or tobramycin in the treatment of febrile episodes in cancer patients. Am J Med 1979, 67(4):608-16.

16. Buck C, Bertram N, Ackermann T, Sauerbruch T, Derendorf H, Paar WD: Pharmacokinetics of piperacillin-tazobactam: intermittent dosing versus continuous infusion. Int J Antimicrob Agents 2005, 25(1):62-7.

17. Georges B, Conil JM, Cougot P, Decun JF, Archambaud M, Seguin T, Chabanon G, Virenque C, Houin G, Saivin S: Cefepime in critically ill patients: continuous infusion vs. an intermittent dosing regimen. Int J Clin Pharmacol Ther 2005, 43(8):360-9.

18. Kojika M, Sato N, Hakozaki M, Suzuki Y, Takahasi G, Endo S, Suzuki K, Wakabayasi G: [A preliminary study of the administration of carbapenem antibiotics in sepsis patients on the basis of the administration time]. Jpn J Antibiot 2005, 58(5):452-7.

19. Lagast H, Meunier-Carpentier F, Klastersky J: Treatment of gram-negative bacillary septicemia with cefoperazone. Eur J Clin Microbiol 1983, 2(6):554-8.

20. Lau WK, Mercer D, Itani KM, Nicolau DP, Kuti JL, Mansfield D, Dana A: Randomized, open-label, comparative study of piperacillin-tazobactam administered by continuous infusion versus intermittent infusion for treatment of hospitalized patients with complicated intra-abdominal infection. Antimicrob Agents Chemother 2006, 50(11):3556-61.

21. Merchant S, Gast C, Nathwani D, Lee M, Quintana A, Ketter N, Friedland I, Ingham M: Hospital resource utilization with doripenem versus imipenem in the treatment of ventilator-associated pneumonia. Clin Ther 2008, 30(4):717-33.

22. Rafati MR, Rouini MR, Mojtahedzadeh M, Najafi A, Tavakoli H, Gholami K, Fazeli MR: Clinical efficacy of continuous infusion of piperacillin compared with intermittent dosing in septic critically ill patients. Int J Antimicrob Agents 2006, 28(2):122-7.

23. van Zanten AR, Oudijk M, Nohlmans-Paulssen MK, van der Meer YG, Girbes AR, Polderman KH: Continuous vs. intermittent cefotaxime administration in patients with chronic obstructive pulmonary disease and respiratory tract infections: pharmacokinetics/pharmacodynamics, 
bacterial susceptibility and clinical efficacy. Br I Clin Pharmacol 2007, 63(1):100-9.

24. Chastre J, Wunderink R, Prokocimer P, Lee M, Kaniga K, Friedland I: Efficacy and safety of intravenous infusion of doripenem versus imipenem in ventilator-associated pneumonia: a multicenter, randomized study. Crit Care Med 2008, 36(4):1089-96

25. Grant EM, Kuti JL, Nicolau DP, Nightingale C, Quintiliani R: Clinical efficacy and pharmacoeconomics of a continuous-infusion piperacillintazobactam program in a large community teaching hospital. Pharmacotherapy 2002, 22(4):471-83

26. Lodise TP Jr, Lomaestro B, Drusano GL: Piperacillin-tazobactam for Pseudomonas aeruginosa infection: clinical implications of an extendedinfusion dosing strategy. Clin Infect Dis 2007, 44(3):357-63.

27. Lorente L, Jimenez A, Martin MM, Iribarren JL, Jimenez JJ, Mora ML: Clinical cure of ventilator - associated pneumonia treated with piperacillin/ tazobactam administered by continuous or intermittent infusion. Int $\lrcorner$ Antimicrob Agents 2009, 33(5):464-8.

28. Patel GW, Patel N, Lat A, Trombley K, Enbawe S, Manor K, Smith R, Lodise TP: Outcomes of extended infusion piperacillin/tazobactam for documented Gram-negative infections. Diagn Microbiol Infect Dis 2009, 64(2):236-40

29. Lorente L, Jimenez A, Palmero S, Jimenez JJ, Iribarren JL, Santana M, Martin MM, Mora ML: Comparison of clinical cure rates in adults with ventilator-associated pneumonia treated with intravenous ceftazidime administered by continuous or intermittent infusion: a retrospective, nonrandomized, open-label, historical chart review. Clin Ther 2007, 29(11):2433-9.

30. Lorente L, Lorenzo L, Martin MM, Jimenez A, Mora ML: Meropenem by continuous versus intermittent infusion in ventilator-associated pneumonia due to gram-negative bacilli. Ann Pharmacother 2006, 40(2):219-23.

31. Roberts JA, Webb S, Paterson D, Ho KM, Lipman J: A systematic review on clinical benefits of continuous administration of beta-lactam antibiotics. Crit Care Med 2009, 37(6):2071-8.

32. Kasiakou SK, Sermaides GJ, Michalopoulos A, Soteriades ES, Falagas ME: Continuous versus intermittent intravenous administration of antibiotics: a meta-analysis of randomised controlled trials. Lancet Infect Dis 2005, 5(9):581-9.

33. Bourgeois FT, Murthy S, Mandl KD: Outcome reporting among drug trials registered in ClinicalTrials.gov. Ann Intern Med 2010, 153(3):158-66.

34. Mckinnon PS, Paladino JA, Schentag JJ: Evaluation of area under the inhibitory curve (AUIC) and time above the minimum inhibitory concentration $(\mathrm{T}>\mathrm{MIC})$ as predictors of outcome for cefepime and ceftazidime in serious bacterial infections. Int J Antimicrob Agents 2008 31(4):345-51

\section{Pre-publication history}

The pre-publication history for this paper can be accessed here: http://www.biomedcentral.com/1471-2334/11/181/prepub

doi:10.1186/1471-2334-11-181

Cite this article as: Tamma et al.: Does prolonged $\beta$-lactam infusions improve clinical outcomes compared to intermittent infusions? A metaanalysis and systematic review of randomized, controlled trials. $B M C$ Infectious Diseases 2011 11:181.

\section{Submit your next manuscript to BioMed Central and take full advantage of:}

- Convenient online submission

- Thorough peer review

- No space constraints or color figure charges

- Immediate publication on acceptance

- Inclusion in PubMed, CAS, Scopus and Google Scholar

- Research which is freely available for redistribution 